\title{
MICROALBUMINURIA: ASSOCIATION WITH DYSLIPIDAEMIA IN TYPE 2 DIABETES MELLITUS
}

\author{
Srinivasa Kaligonahalli Venkataramanappa ${ }^{1}$, Parashuram ${ }^{2}$ \\ ${ }_{1}^{1}$ Associate Professor, Department of Medicine, Dr. B. R. Ambedkar Medical College and Hospital, Bangalore. \\ ${ }^{2}$ Assistant Professor, Department of Medicine, Dr. B. R. Ambedkar Medical College and Hospital, Bangalore.
}

\section{ABSTRACT}

\section{BACKGROUND AND OBJECTIVES}

Diabetes Mellitus is the commonest metabolic disorder affecting the people all over the world. Diabetic nephropathy is one of the common complications. The relationship between dyslipidaemia and microalbuminuria is of special interest in Indian population on account of significant insulin resistance, which may be the common link between microalbuminuria and dyslipidaemia. This study was conducted to study the lipid profile in micro and normoalbuminuric type 2 diabetics.

\section{METHODS}

50 type 2 diabetic patients admitted in medical wards of Karnataka Institute of Medical Sciences, Hubli, between November 2004 to October 2005 and 20 age and sex matched healthy controls were taken in the study; 24-hour urine albumin estimation and lipid profile was done. Study group was divided into three categories, microalbuminuria, normoalbuminuria and healthy controls. Results were compared using suitable statistical methods (Student's " $t$ ” test and Fischer's exact test).

\section{RESULTS}

Lipid profile with total cholesterol $219.2 \pm 47.3$ and $181.87 \pm 21.1 \mathrm{mg} / \mathrm{dL}$, triglycerides 190.9 and 142.21 \pm 15.1 , mean LDL-C $140.3 \pm 43$ and $113.6 \pm 24$, VLDL $38.3 \pm 18.5$ and $28.7 \pm 2.9$ respectively in micro and normoalbuminuria. Study showed significantly higher levels of total cholesterol, triglycerides, LDL-C and VLDL in microalbuminuria group. No significant change in HDL-C level in both groups. Retinopathy with the prevalence of $77.77 \%$ and $15.6 \%$, neuropathy with the prevalence of $55.53 \%$ and $12.5 \%$ respectively was seen in micro and normoalbuminuria groups.

\section{CONCLUSION}

Though lipid profile was deranged in both micro and normoalbuminuric diabetics, the mean levels of total cholesterol, triglycerides, LDL-C, VLDL were significantly increased in microalbuminuria. No significant change in HDL-C level. Whether the qualitative and quantitative alteration in lipids is a cause or result of the disease remains to be studied.

\section{KEYWORDS}

Triglycerides; Total cholesterol; LDL-C; VLDL; HDL-C; Microalbuminuria.

HOW TO CITE THIS ARTICLE: Venkataramanappa SK, Parashuram. Microalbuminuria: association with dyslipidaemia in type 2 diabetes mellitus. J. Evolution Med. Dent. Sci. 2016;5(48):3048-3052, DOI: 10.14260/jemds/2016/710

\section{INTRODUCTION}

Diabetes mellitus is the commonest metabolic disorder affecting the people all over the world. Diabetic nephropathy, which occurs in as many as $30 \%$ of type 1 diabetes and $25 \%$ of type 2 diabetics. Diabetic nephropathy is an important cause of morbidity and mortality and is among the most common causes of end stage renal failure. However, there is an early phase of diabetic renal disease called incipient diabetic nephropathy. ${ }^{1}$

In this stage, there is a rise in urinary excretion of albumin (Microalbuminuria). Microalbuminuria precedes the development of overt diabetic nephropathy by 10-14 years. Microalbuminuria is most often associated with other microvascular complications of diabetes namely retinopathy, neuropathy. So Microalbuminuria may be a marker for widespread microvascular damage in diabetic individual.

Financial or Other, Competing Interest: None.

Submission 16-05-2016, Peer Review 28-05-2016,

Acceptance 31-05-2016, Published 14-06-2016.

Corresponding Author:

Dr. Srinivasa Kaligonahalli Venkataramanappa,

Associate Professor,

Department of Medicine,

Dr. B. R. Ambedkar Medical College and Hospital,

Bangalore.

E-mail: drsrinivas08@gmail.com

DOI: $10.14260 /$ jemds $/ 2016 / 710$
Hyperlipidaemia is a common problem in patients with diabetes. The relationship between elevation of serum lipids and vascular complications is more significant in diabetics than in general population. ${ }^{2}$ Abnormalities of lipid level accounts for microvascular and macrovascular disease in diabetic patients.

The relationship between dyslipidaemia and microalbuminuria is of special interest in Indian population on account of significant insulin resistance, which may be the common link between microalbuminuria and dyslipidaemia.

Of the small quantity of the albumin and IgG normally filtered at the glomerulus $95-97 \%$ is reabsorbed by the proximal tubules. The reabsorptive process is working at maximal capacity, so that moderate increase in filtered protein is reflected in an elevation of its urinary excretion rate.

The microalbuminuria and micro IgG uria of diabetes are glomerular in origin and associated with normal tubular function. It is supported by finding of a normal excretion of $\beta_{2}$ microglobulin a sensitive indicator of tubular reabsorptive capacity.

In diabetics, the enlarged filtration surface area would probably result in greater number of pores (No larger pores have been shown at this stage).

As microalbuminuria becomes persistent and increases in degree, the sensitivity index i.e. clearance of $\operatorname{Ig} G /$ clearance of 
albumin starts to fall reaching its lowest values when albumin excretion is around $90 \mathrm{mcg} / \mathrm{min}$ are higher. This is due to disproportionate increase in albumin. At this stage, medium sized pores are unchanged and likely reason is a loss of fixed negative electrical charge on the membrane. This would permit increased permeation of anionic albumin, but has little

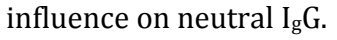

\section{CONCOMITANTS OF MICROALBUMINURIA \\ [The Microalbuminuria Syndrome]}

- $\quad$ Elevated Blood pressure.

- $\quad$ Atherogenic lipid profile [个VLDL-triglycerides, $\downarrow$ HDL cholesterol, $\uparrow$ Lp (a)].

- Elevated plasma fibrinogen.

- Decreased insulin sensitivity.

- Increased total body exchangeable sodium.

- Increased transcapillary escape of albumin.

- Impaired basal endothelium dependent vasorelaxation.

- Increased left ventricular volume.

- Diabetic retinopathy.

- Silent ischaemic heart disease.

- Increased prevalence of peripheral vascular disease.

Atherogenic lipid profile [Increased VLDL-TG, Lp (a), decreased HDL-C] is regarded as one of the concomitants of microalbuminuria. ${ }^{3}$

In the heart protection study, $40 \mathrm{mg}$ simvastatin reduced the rate of major vascular events and GFR decline in patients with diabetes independent of cholesterol levels at baseline by $53 \%{ }^{4}$

Aldersberg et al (1963) studied 139 diabetics over a period of 30 years with regard to serum lipid concentration and the vascular complications of diabetes mellitus and found a trend towards increasing serum triglyceride concentrations and increasing incidence of atherosclerosis in coronary and other arteries.

This study was done mainly to study the lipid profile in type 2 diabetes, compare lipid profile in microalbuminuric with normoalbuminuric patients of type 2 diabetes and to study the profile of microvascular complications in microalbuminuric patients with type 2 diabetes.

\section{METHODOLOGY}

This study was conducted on all patients of type 2 diabetes meeting inclusion and exclusion criteria admitted in the medical wards of KIMS Hospital, Hubli, between $1^{\text {st }}$ November 2004 and 31st October 2005.

Ethical clearance was obtained from Institutional Ethical Committee. Case of type 2 diabetes mellitus according to ADA criteria were included in the study.

\section{Exclusion Criteria}

- Overt diabetic nephropathy (Albuminuria >300 $\mathrm{mg} /$ day).

- Renal disease.

- Hypertension.

- Coronary artery disease.

- Congestive heart failure.

- Urinary tract infection.

- Recent intercurrent illness.

\section{STUDY POPULATION DIVIDED INTO 3 GROUPS}

Group I: Age and sex matched healthy controls.

Group II: Type 2 Diabetes with microalbuminuria.

Group III: Type 2 Diabetes with normoalbuminuria.

Age and sex matched relatives of patients were used as controls who were normoalbuminuric.

All the subjects were interviewed as per the prepared proforma and then complete clinical examination is carried out with special emphasis on detection of peripheral neuropathy-present: If history of neuropathic pain, numbness, tingling and/or absence of ankle jerk, diminished vibratory threshold, pinprick in hand or foot.

\section{Retinopathy}

- Non-proliferative with evidence of micro aneurysms/soft or hard exudates/haemorrhages.

- Proliferative with neovascularization.

- $\quad$ Spot sample of urine was checked and 30-300 mg/g of creatinine was considered as microalbuminuria and less than $30 \mathrm{mg} / \mathrm{g}$ of creatinine was normoalbuminuria.

- $\quad$ Lipid profile was done in fasting blood samples.

- $\quad$ Fasting (minimum 8 hours), blood sample was collected. Levels of total cholesterol, TG, HDL-C are measured by standard enzymatic methods. VLDL-TG and LDL-C were calculated by standard WHO approved formula.

VLDL=TG $/ 5$.

LDL=Total Cholesterol-(HDL+VLDL) according to ATP III Guidelines Normal Levels were taken as:

Total Cholesterol: $<200 \mathrm{mg} / \mathrm{dL}$.

LDL-C: $<100 \mathrm{mg} / \mathrm{dL}$.

TG: $<150 \mathrm{mg} / \mathrm{dL}$.

HDL: $>40 \mathrm{mg} / \mathrm{dL}$.

Statistical analysis was done using Student's " $\mathrm{t}$ " test and Fisher's exact test.

\section{RESULTS}

In our study, 50 patients of type 2 diabetes and 20 age and sex matched healthy controls were studied.

In this study of 50 patients of type 2 diabetes, 18 patients had microalbuminuria giving prevalence of $36 \%$. Among these patients, 28 patients were males and 22 were females. Among male patients, 10 (35.71\%) patients were positive for microalbuminuria.

The mean age at detection of microalbuminuria was $52.5 \pm 4.67$. Mean age of patients with normoalbuminuria was $49.94 \pm 4.57$, which is statistically not significant. In the present study maximum number of patients 24 (48\%) had duration of diabetes between 0-5 years. Among these 1 $(4.17 \%)$ patient had microalbuminuria; 14 (28\%) patients were with duration between 5-10 years. Among them 5 (35.71\%) had microalbuminuria; $6(12 \%)$ patients each were with duration 11-15 years and $>15$ years. All of them were positive for microalbuminuria. 


\begin{tabular}{|c|c|c|c|c|c|}
\hline \multirow{2}{*}{$\begin{array}{c}\text { Duration of } \\
\text { Diabetes } \\
\text { (Years) }\end{array}$} & $\begin{array}{c}\text { Total No. } \\
\text { of Cases }\end{array}$ & $\begin{array}{c}\text { Microalbuminuria } \\
\text { No. of } \\
\text { Cases }\end{array}$ & $\%$ & $\begin{array}{c}\text { Normoalbuminuria } \\
\text { Cases }\end{array}$ & $\%$ \\
\hline $0-5$ & 24 & 1 & 4.17 & 23 & 95.83 \\
\hline $6-10$ & 14 & 5 & 35.71 & 9 & 64.29 \\
\hline $11-15$ & 6 & 6 & 100.00 & 0 & 0 \\
\hline$>15$ years & 6 & 6 & 100.00 & 0 & 0 \\
\hline Total & $\mathbf{5 0}$ & $\mathbf{1 8}$ & & 32 & \\
\hline Mean \pm SD & $12.72 \pm 4.08$ & $4.09 \pm 2.26$ \\
\hline \multicolumn{6}{|c|}{ t=9.65 p value< $<0.001$} \\
\hline \multicolumn{7}{|c|}{ Prevalence of Microalbuminuria in } \\
Relation to Duration of Diabetes \\
\hline
\end{tabular}

Mean duration of diabetes in microalbuminuric patients was $12.72 \pm 4.08$ years, while in normoalbuminuric patients was $4.09 \pm 2.26$ years which is statistically significant.

Number of patients with microalbuminuria increase with duration of diabetes, as it is $4.17 \%$ between $0-5$ years and $100 \%$ above 10 years.

Mean FBS in microalbuminuric patients was $171.11 \pm 29.7$ and normoalbuminuric patients $132.06 \pm 18.9$, which was statistically significant.

Mean PPBS in microalbuminuric patients was $294.83 \pm 34.3$ and in normoalbuminuric patients was $218.34 \pm 25.7$, which was statistically highly significant.

In the present study, the prevalence of complications was significantly higher in microalbuminuric group.

\begin{tabular}{|c|c|c|c|c|c|c|}
\hline \multirow{2}{*}{$\begin{array}{l}\text { Compli- } \\
\text { cation }\end{array}$} & \multirow{2}{*}{$\begin{array}{l}\text { Total } \\
\text { No. of } \\
\text { Cases }\end{array}$} & \multicolumn{2}{|c|}{$\begin{array}{l}\text { Micro- } \\
\text { albuminuria } \\
\qquad(n=18)\end{array}$} & \multicolumn{2}{|c|}{$\begin{array}{c}\text { Normo- } \\
\text { albuminuria } \\
(n=32)\end{array}$} & \multirow{2}{*}{$\begin{array}{c}\text { p value } \\
\text { (Fisher's } \\
\text { exact } \\
\text { test) }\end{array}$} \\
\hline & & $\begin{array}{l}\text { No. of } \\
\text { Cases }\end{array}$ & $\%$ & $\begin{array}{l}\text { No. of } \\
\text { Cases }\end{array}$ & $\%$ & \\
\hline $\begin{array}{c}\text { Diabetic } \\
\text { Retinopathy }\end{array}$ & 19 & 14 & 77.77\% & 5 & $15.6 \%$ & $<0.001$ \\
\hline $\begin{array}{l}\text { Peripheral } \\
\text { Neuropathy }\end{array}$ & 14 & 10 & $55.55 \%$ & 4 & $12.5 \%$ & $<0.001$ \\
\hline
\end{tabular}

The total cholesterol, triglycerides, LDL-C and VLDL were significantly higher and HDL-C significantly lower in microalbuminurics compared to healthy controls.

The total serum cholesterol was $219.2 \pm 47.3$ in microalbuminuric patients, whereas in normoalbuminuric patients $181.87 \pm 21.1 \mathrm{mg} / \mathrm{dL}$, which is statistically significant.

Triglycerides in microalbuminuric was $190.9 \pm 93.4$ and in normoalbuminuric was $142.22 \pm 15.1 \mathrm{mg} / \mathrm{dL}$, which is statistically significant.

LDL-Cholesterol is $140.3 \pm 43$ in microalbuminuric and $113.65 \pm 24$ in normoalbuminuric patients. VLDL $38.3 \pm 18.5$ and $28.75 \pm 2.9 \mathrm{mg} / \mathrm{dL}$ respectively in micro and normoalbuminurics, which is significantly higher in microalbuminuric group.

Mean HDL-C $40.39 \pm 8.6$ in microalbuminuric and $39.28 \pm 3.1 \mathrm{mg} / \mathrm{dL}$ in normoalbuminurics.

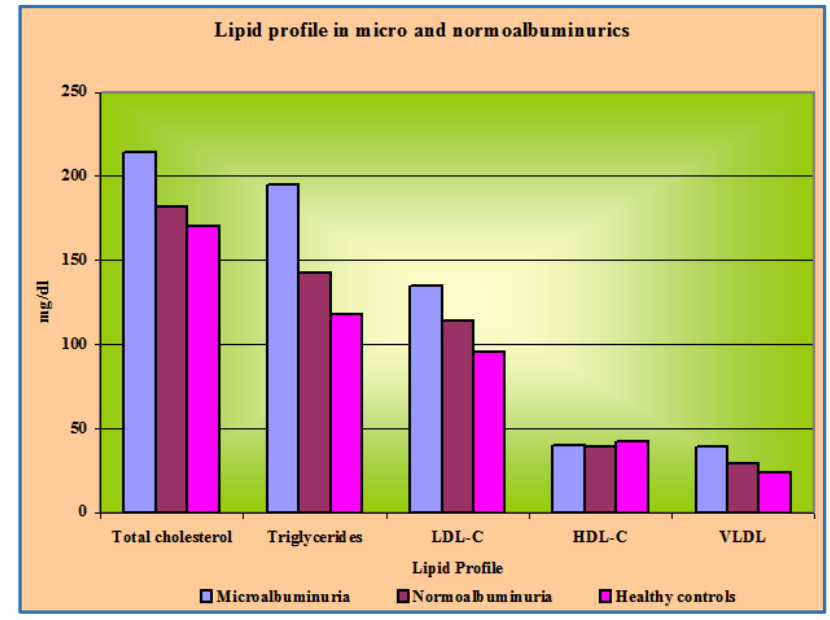

Total cholesterol, triglycerides, LDL-C, VLDL are significantly higher in both micro and normoalbuminuric diabetics and HDL-C was significantly lower when compared to age and sex matched healthy controls.

Within diabetics the total cholesterol, triglycerides, LDLC, VLDL are significantly higher in micro group compared to normoalbuminurics. No significant change in HDL-C levels between both the groups.

\section{DISCUSSION}

$\mathrm{V}$ Taneja et al found mean duration as $12.57 \pm 6.3$ years and $4.5 \pm 2.9$ years respectively for microalbuminuria and normoalbuminuria, which is comparable to present study.

K. Jaishankar et al found mean duration as $15.52 \pm 4.49$ and $9.91 \pm 4.95$ years respectively for micro and normoalbuminuria.

\begin{tabular}{|c|c|c|c|c|c|}
\hline \multirow{2}{*}{$\begin{array}{l}\text { Sl. } \\
\text { No. }\end{array}$} & \multirow{2}{*}{ Study } & \multicolumn{2}{|c|}{ FBS (mg/dL) } & \multicolumn{2}{|c|}{ PPBS (mg/dL) } \\
\hline & & Micro & Normo & Micro & Normo \\
\hline 1 & $\begin{array}{c}\text { V. Taneja } \\
\text { et al }{ }^{4}\end{array}$ & 176.1 & 144 & 272.3 & 221.3 \\
\hline 2 & $\begin{array}{c}\text { K. } \\
\text { Jaishankar } \\
\text { F et al }{ }^{5}\end{array}$ & 208.16 & 132.2 & 299.61 & 207.4 \\
\hline 3 & $\begin{array}{c}\text { Present } \\
\text { study }\end{array}$ & 171.11 & 132.06 & 294.83 & 218.34 \\
\hline
\end{tabular}

In the present study, the mean FBS was $171.11 \mathrm{mg} / \mathrm{dL}$ and $132.06 \mathrm{mg} / \mathrm{dL}$ and PPBS was 294.83 and $218.34 \mathrm{mg} / \mathrm{dL}$ respectively in microalbuminurics and normoalbuminurics.

In various studies like $\mathrm{K}$, Jaishankar et al found mean FBS 208.16 and 132.2 and PPBS 299.61 and 207.4 respectively in micro and normoalbuminuria.

\begin{tabular}{|c|c|c|c|c|c|}
\hline \multirow{2}{*}{$\begin{array}{c}\text { Sl. } \\
\text { No. }\end{array}$} & \multirow{2}{*}{ Study } & $\begin{array}{c}\text { Prevalence of } \\
\text { Retinopathy }\end{array}$ & $\begin{array}{c}\text { Prevalence of } \\
\text { Neuropathy }\end{array}$ \\
\cline { 3 - 6 } & Micro & Normo & Micro & Normo \\
\hline 1 & V. Taneja et al & $84.2 \%$ & $15.8 \%$ & $63.2 \%$ & $21.6 \%$ \\
\hline 2 & $\begin{array}{c}\text { KL Patel } \\
\text { et al }\end{array}$ & $33.33 \%$ & $34.25 \%$ & $55.5 \%$ & $42.5 \%$ \\
\hline 3 & $\begin{array}{c}\text { K. Jaishankar } \\
\text { et al }\end{array}$ & $76 \%$ & $38.6 \%$ & $\begin{array}{c}\text { No significant } \\
\text { difference }\end{array}$ \\
\hline 4 & Present study & 77.77 & 15.6 & 55.55 & 12.5 \\
\hline \multicolumn{5}{|c|}{$\begin{array}{c}\text { Showing Prevalence of Various Complications } \\
\text { in Microalbuminuria }\end{array}$} \\
\hline \multicolumn{6}{|c|}{}
\end{tabular}


Incipient diabetic nephropathy is a common complication of type 2 diabetes with the prevalence of $36 \%$. The prevalence of microalbuminuria increases with duration of diabetes irrespective of the age. The other microvascular complications like retinopathy and peripheral neuropathy are more prevalent with microalbuminuria indicating microalbuminuria as a biomarker of widespread vascular damage.

\section{Various Metabolic Pathways can be Explained as Hyperglycaemia}

There is overwhelming evidence linking hyperglycaemia to diabetic microvascular and macrovascular complications. In humans the evidence of straightforward causal relationship between hyperglycaemia and renal disease is less compelling than it is in the animal model. It appears that hyperglycaemia is necessary, but not sufficient and possibly nonenvironmental factors are needed for manifestations of the clinical syndrome.

\section{Non-Enzymatic Glycosylation}

The exposure of lysine amino terminal groups of proteins to high glucose concentrations lead to increased covalent bonding of glucose to proteins. These covalent products can then participate in cross-linking between or within protein molecules producing Advanced Glycosylation End Products (AGE).

The Possible Mechanisms of Non-Enzymatic Glycosylation Contributing to Diabetic Complications

- AGE may alter the structure and functions of extracellular matrix by cross-linking matrix proteins.

- $\quad$ AGE may affect the activity of signals, such as cytokine growth factors and free radicals by interacting with AGE receptors on various tissues.

- Glycation may directly affect the functions of enzymes and other key intracellular proteins.

\section{The Polyol Pathway}

Sorbitol is produced in cells from glucose by reaction catalysed by aldolase reductase. Chronic hyperglycaemia may lead to sorbitol accumulation in variety of tissues including renal tubules and glomeruli, which could cause tissue damage, perhaps by disturbing cellular osmoregulation and depleting intracellular myoinositol.

\section{Biochemical Abnormalities of Extracellular Matrix}

Diabetic glomerulopathy is characterized by excessive accumulation of glomerular basement membrane and mesangial matrix. The activity of lysyl hydroxylase required for collagen synthesis has been found to be increased.

In diabetes there is reduced de novo synthesis of glomerular heparan sulphate and total glomerular glycosaminoglycans. There are reduced negatively charged sialoglycoproteins resulting in foot process fusion.

\section{Glucotoxicity}

Glucose itself may have direct toxic effect on cells. Lorenzi et al, has demonstrated cultured human endothelial cells that are chronically exposed to high glucose concentrations show abnormalities like alteration in cell replication and maturation. High glucose level lead to increased expression and synthesis of collagen, fibronectin and laminin.

\section{Haemodynamic and Hypertrophic Pathways}

Glomerular haemodynamic disturbances with elevation of renal blood flow and GFR occurring early in the course of diabetes have suggested that they are directly responsible for development of glomerulosclerosis.

Marked renal hypertrophy is an early event in diabetes, which argues that hypertrophic changes precede the haemodynamic abnormalities.

\section{Familial/Genetic Pathways}

There is ever growing evidence that the degree of diabetic control is only a necessary component, but is not linearly related. Alternative hypothesis has been advocated taking account the host response to diabetic induced environmental disturbances. Familial influence on development of nephropathy has been described in Pima Indians with NIDDM.

\section{Various Complications in Microalbuminuric Patient}

In the present study the prevalence of diabetic retinopathy was $77.77 \%$ and $15.6 \%$ respectively in micro and normoalbuminurics. The prevalence of peripheral neuropathy was $55.55 \%$ and $12.5 \%$ in micro and normoalbuminurics respectively.

The GFR may be normal or even raised at the onset, but will proceed to relentlessly fall, its rate of decline ranging from 0.1-2.4 $\mathrm{mL} / \mathrm{min} / \mathrm{month}$. By the stage of macroproteinuria, albumin represents approximately $50 \%$ of total urinary proteins, whereas in normoproteinuria is up to $11 \%$ and in microproteinuria is up to $22 \%$ respectively.

Elevated serum lipoprotein levels can accelerate endothelial cell damage and cause cholesterol ester accumulation and muscle cell proliferation. The early diabetic nephropathy can itself influence lipoprotein metabolism and excretion and thus set up a vicious cycle of microvascular damage. Whether the quantitative and qualitative alteration in lipids is a cause or result of the disease remains to be studied.

\section{Dyslipidaemia and Type 2 Diabetes}

The most common anomaly in type 2 Diabetes is hypertriglyceridemia caused by increase in VLDL. The effect on TG is moderate. The mechanism of overproduction of VLDL-TG because of increased flow of glucose and free fatty acids to the liver and the impaired clearance is by impaired lipoprotein, lipase activity. The mechanism of increased LDL$\mathrm{C}$ is both increased production and decreased clearance. Nonenzymatic glycosylation of LDL Apo B occurs with poor diabetic control and interferes with LDL catabolism. Common cause of increased LDL is development of diabetic nephropathy and nephrotic syndrome.

HDL, which is consistently low especially HDL2. The mechanism appears to be increased catabolism and reduced production, the former being related to increased hepatic lipase activity.

\section{HYPERLIPIDEMIC SYNDROMES ASSOCIATED WITH DIABETICS}

\section{Chylomicronemia Syndrome}

Diabetic lipemia is a rare, but well-recognized manifestation of uncontrolled diabetes caused by accumulation of chylomicrons and VLDL. In many individuals with type 2 DM insulin treatment ameliorates severe hypertriglyceridemia, 
but does not return plasma lipid values to normal. For this group, the term chylomicronemia syndrome is used, which is a result of interaction of genetic and secondary forms of hyperlipidemia. They require lipid-lowering therapy along with treatment of diabetes.

\section{Primary Diabetes and Secondary Hyperlipidemia}

This is frequently seen during poor diabetic control and rarely develop increase in $\mathrm{TG}>500 \mathrm{mg} / \mathrm{dL}$ and often only mild-to-moderate hypercholesterolemia. Both of which return to normal after treatment of diabetes. Occasionally develop hypercholesterolemia alone with good diabetic control because of carbohydrate restricted and high fat diet.

\section{Primary Hyperlipidaemia and Secondary Glucose Intolerance}

An increased incidence of abnormal glucose intolerance has been reported in individuals with various primary forms of hyperlipidemia (Glueck, C. J., 1969). The reason for this may be obesity, common in primary hyperlipidemia this may result in insulin resistance [Bierman E. L., 1968]. The clinical significance is treatment of hyperlipidemia frequently results in amelioration of glucose intolerance.

\section{Primary Diabetes and Primary Hyperlipidemia}

The diabetes and genetic form of hypertriglyceridemia appear to be independent entities, which may happen to coexist by chance.

K. Jaishankar et al noted the prevalence of retinopathy as $76 \%$ and $38.6 \%$ respectively in micro and normoalbuminurics. Parving et al found the prevalence of retinopathy and neuropathy as $26 \%$ and $31 \%$ respectively in microalbuminurics. V. Taneja et al noted the prevalence of retinopathy to be $84.2 \%$ and $15.8 \%$ respectively in micro and normoalbuminurics. In the same study, the prevalence of neuropathy was $63.2 \%$ and $21.6 \%$ respectively in micro and normoalbuminurics.

Mishra Umashankar et al $^{7}$ found total cholesterol 192 \pm 10 , $183 \pm 10$, triglyceride $194 \pm 9,155 \pm 16$, LDLC $113 \pm 13,106 \pm 11$, HDLC $40 \pm 4,43 \pm 4$, VLDL $39 \pm 3,31 \pm 4$ respectively in micro and normoalbuminuria diabetics.

\section{CONCLUSION}

Incipient diabetic nephropathy is a common complication of type 2 diabetes with the prevalence of $36 \%$. The prevalence of microalbuminuria increases with duration of diabetes irrespective of the age. Uncontrolled diabetes in the form of higher FBS and PPBS is associated with microalbuminuria. The other microvascular complications like retinopathy and peripheral neuropathy are more prevalent with microalbuminuria indicating microalbuminuria as a biomarker of widespread vascular damage.

The lipid profile is deranged in both the groups. The mean levels of total cholesterol, triglycerides, LDL-C, VLDL are significantly higher in micro group compared to normoalbuminurics, whereas HDL-C was similar in both groups. Elevated serum lipoprotein levels can accelerate endothelial cell damage and cause cholesterol ester accumulation and muscle cell proliferation. The early diabetic nephropathy can itself influence lipoprotein metabolism and excretion and thus set up a vicious cycle of microvascular damage. Whether the quantitative and qualitative alteration in lipids is a cause or result of the disease remains to be studied.

\section{REFERENCES}

1. Deckert T, Poulsen JE, Larson M. Prognosis of diabetics with diabetes onset before the age of thirty-onei survival, causes of death, and complications. Diabetologia 1978;14(6):363-70.

2. William B Kannel. Lipids, diabetes and coronary heart disease: insights from the framingham study. Am Heart J 1985;110(5):1100-7.

3. Trevison R, Viberti G. Pathophysiology of diabetic nephropathy-diabetes mellitus: a fundamental and clinical text, Derek RL, Taylor SI, Jerrold M Olefsky (ed). Philadelphia, Lipincott Williams and Wilkins, 2000;2nd ed:898-908.

4. Taneja V, Sircar S, Kansra U, et al. Microalbuminuria: association with dyslipidaemia in NIDDM. J Assoc Phy India 1997;45(8):608-11.

5. Jaishankar K, RiazHussain, Ramon PG. Prevalence of microalbuminuria in diabetes mellitus and its correlation with various complications. J Diab Assoc India 1996;36(3):77-80.

6. Patel KL, Mhetras SB, Varthakavi, et al. Microalbuminuria in non-insulin dependent diabetes mellitus. J Assoc Phy India 1999;47(6):596-601.

7. Mishra Umashankar, Ray Gandharba, Mohanty Rina, et al. Lipoprotein abnormalities in type 2 diabetes with microalbuminuria. J Assoc Phy India 2003;31:1167. 